06

\title{
Полуполярные $\mathrm{GaN}-с л о и ~$ \\ на наноструктурированной \\ Si(100)-подложке
}

\author{
(C) В.Н. Бессолов ${ }^{1}$, Е.В. Коненкова ${ }^{1}$, Т.А. Орлова ${ }^{1}$, С.Н. Родин ${ }^{1}$, \\ М.П. Щеглов ${ }^{1}$, Д.С. Кибалов ${ }^{2}$, В.К. Смирнов ${ }^{2}$ \\ ${ }^{1}$ Физико-технический институт им. А.Ф. Иоффре РАН, Санкт-Петербург, \\ Россия \\ ${ }^{2}$ ООО „Квантовый кремний“, Москва, Россия \\ E-mail: bes.triat@mail.ioffe.ru
}

Поступило в Редакцию 19 февраля 2018 г.

\begin{abstract}
Предложен новый метод синтеза $\mathrm{GaN}$ в полуполярном направлении на подложке $\mathrm{Si}(100)$, на поверхности которой сформирована $V$-образная наноструктура с суб-100 nm размером элементов. Показано, что применение наноструктурированной подложки в методе газофазной эпитаксии из металлоорганических соединений позволяет формировать слой, направление роста которого отклонено от полярного направления на угол около $62^{\circ}$ при минимальной полуширине рентгенодифракционной кривой качания $\mathrm{GaN}(10 \overline{1} 1) \omega_{\theta} \sim 60 \mathrm{arcmin}$.
\end{abstract}

DOI: 10.21883/PJTF.2018.12.46290.17260

Приборы нитрид-галлиевой электроники создаются в основном на основе структур, синтезированных в направлении [0001] оси с гексагонального кристалла GaN. Однако использование (0001)-плоскости $\mathrm{GaN}$ в оптоэлектронных приборах приводит к появлению эффекта Штарка из-за сильной пьезоэлектрической поляризации. Для того чтобы избежать негативного влияния этого эффекта, в последние годы создаются оптоэлектронные приборы на основе неполярных и полуполярных структур $\mathrm{GaN}$. В настоящее время предпринимаются попытки синтезировать полуполярный $\mathrm{GaN}$ в основном на подложках из сапфира [1], $\mathrm{SiC}[2]$ и кремния $[3,4]$. Синтез полуполярного $\mathrm{GaN}$ осуществляется как на подложках $\mathrm{Si}(11 h)$ (где $h=2-7)[1,5]$, так и на разориентированных подложках $\operatorname{Si}(100)$ [6,7], а также с использованием буферных слоев $3 C$-SiC $[8,9]$. В работах [10-12] для синтеза полупо- 
лярного $\mathrm{GaN}$ использовались литографические структуры микронного масштаба на поверхности $\mathrm{Si}(100)$.

Единственным известным примером синтеза $\mathrm{GaN}$ с использованием структуры с суб-100 $\mathrm{nm}$ размером элементов на поверхности $\mathrm{Si}(100)-$ nanopatterned silicon $(N P-\mathrm{Si}(100))$ - является работа [13], где авторы с помощью электронно-лучевой литографии на локальном участке пластин $\mathrm{Si}(100)$ сформировали массив нанополосок с периодом $100 \mathrm{~nm}$, на котором вырастили слои полярного $\mathrm{GaN}$ с более чем на порядок величины сниженными напряжениями. Синтез полуполярного $\mathrm{GaN}$ на $N P$-Si(100), судя по литературным данным, не проводился.

В настоящей работе сообщается о новом методе синтеза полуполярных слоев нитрида галлия на подложке $N P-\mathrm{Si}(100)$, на поверхности которой $V$-образные канавки сформированы на основе WOSнаномаски (wave-ordered structure) [14,15]. WOS-наномаска является результатом процесса самоформирования на поверхности монокристаллического кремния, слоев аморфного кремния и периодических нанополосок нитрида кремния под действием наклонного потока ионов азота. Период данной нелитографической наномаски задается в интервале $\lambda=30-150 \mathrm{~nm}$. Процессы травления кремния (жидкостные и/или плазмохимические) через WOS-наномаску позволяют формировать $N P-\mathrm{Si}(100)$ с различной геометрией наноэлементов. Следует отметить, что сама WOS-наномаска является асимметричной структурой, поскольку SiN-нанополоски располагаются наклонно с одной стороны склонов канавки. В качестве иллюстрации на рис. 1 приведен результат последовательного применения анизотропного плазмохимического и изотропного кислотного травления кремния через WOSнаномаску с целью формирования нанохребтов треугольного сечения. Видно, что в данной структуре выражена асимметрия, унаследованная от WOS-наномаски.

B настоящей работе был использован аналогичный двухстадийный процесс, включающий плазмохимическое и кислотное травление, для создания наноструктуры в виде плотного массива $V$-образных наноканавок на поверхности $\mathrm{Si}(100)$. На первой стадии проводилось анизотропное плазмохимическое травление кремния через WOS-наномаску с периодом $\lambda=80 \mathrm{~nm}$ с формированием кремниевых нанополос. Для придания наноэлементам треугольной формы сечения на следующей стадии применялось кислотное травление кремния в растворе $\mathrm{HF} / \mathrm{HNO}_{3}$. На поверхности $\mathrm{Si}(100)$ WOS-наномаска была ориентирована вдоль на- 


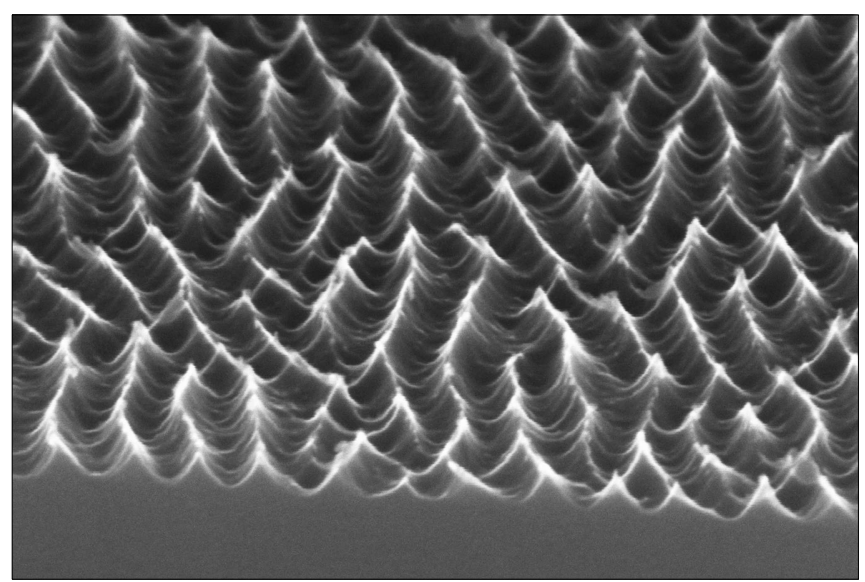

$$
\stackrel{100 \mathrm{~nm}}{\longrightarrow}
$$

Рис. 1. РЭМ-изображение $N P-\mathrm{Si}(100)$ в виде массива нанохребтов с поперечным сечением, близким к треугольному, периодом $\lambda=80 \mathrm{~nm}$ и высотой $45 \mathrm{~nm}$.

правления [110]. На рис. 1 показано полученное методом растровой электронной микроскопии (РЭМ) изображение структуры $N P-\mathrm{Si}(100)$, использованной в последующих экспериментах по эпитаксии.

Слои полуполярного $\mathrm{GaN}$ на подложках $N P-\mathrm{Si}(100)$ были выращены методом газофазной эпитаксии из металлоорганических соединений на модифицированной установке EpiQuip с горизонтальным реактором и индукционно нагреваемым графитовым подложкодержателем [16]. Водород использовался в качестве несущего газа, а аммиак, триметилгаллий и триметилалюминий - в качестве прекурсоров. Структуры состояли из слоя $\mathrm{AlN}$ толщиной $\sim 20 \mathrm{~nm}$ и нелегированного слоя $\mathrm{GaN}$ толщиной $\sim 1 \mu \mathrm{m}$.

Образцы GaN/AlN/Si(100) исследовались методами рентгеновской дифрактометрии (РД) и РЭМ.

Изучение эпитаксиальных структур с помощью РЭМ (рис. 2, $a, b$ ) показало, что поверхность и поперечное сечение слоя имеют характерную структуру полуполярного GaN. Результаты РД указывают на наличие равномерно упорядоченных слоев $\mathrm{GaN}$, направление роста которых отклоняется от полярного направления оси $c$ на угол около $62^{\circ}$

Письма в ЖТФ, 2018, том 44, вып. 12 

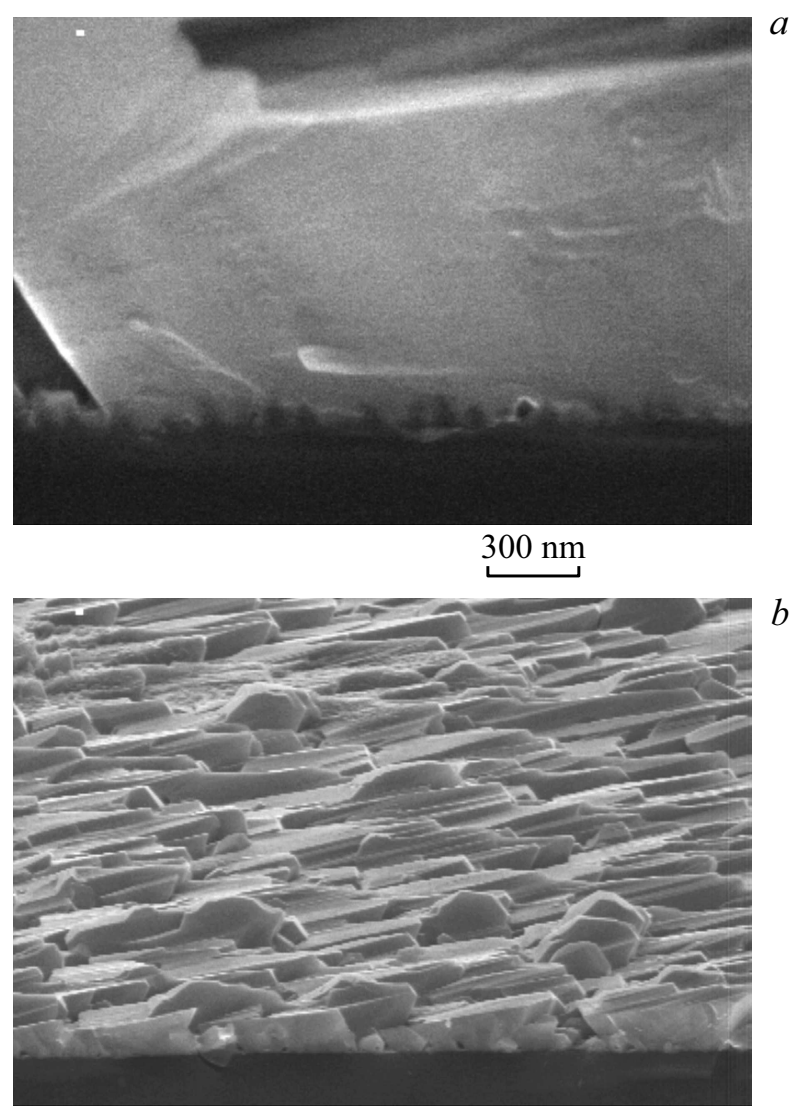

\section{$3 \mu \mathrm{m}$}

Рис. 2. РЭМ-изображения скола $(a)$ и поверхности $(b)$ структуры GaN/AlN/NP-Si(100).

(рис. 2, $a, b)$. Полуширина РД-кривой качания (FWHM) для рефлекса (10ī1) GaN имела значение $\omega_{\theta} \sim 60 \operatorname{arcmin}$.

В работах $[11,12]$ представлены результаты формирования слоев полуполярного $\mathrm{GaN}(1 \overline{1} 01)$ на поверхности $V$-образных микроканавок с гранями (111) на пластине $\mathrm{Si}(100)$. На противоположных склонах

Письма в ЖТФ, 2018, том 44, вып. 12 

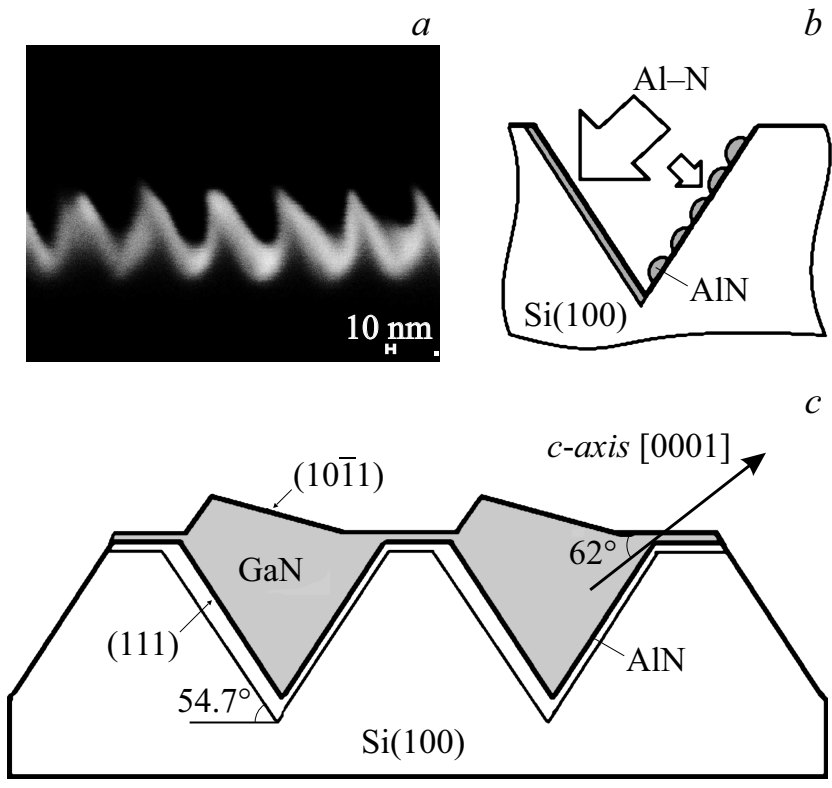

Рис. 3. Схема формирования $\mathrm{GaN}(10 \overline{1} 1)$ на поверхности $N P-\mathrm{Si}(100)$. $a-$ РЭМ-изображение поперечного сечения структуры с периодом $\lambda \sim 90 \mathrm{~nm}$ и размером маркера $10 \mathrm{~nm}$, полученной последовательным плазмохимическим и кислотным травлением Si через WOS-наномаску; $b$ - схема зародышеобразования $\mathrm{AlN}-$ слоя; $c$ - схема синтеза полуполярного $\mathrm{GaN}$.

$V$-образных микроканавок происходил рост полуполярного $\mathrm{GaN}(1 \overline{1} 01)$, но по причине микронного размера канавок слой $\mathrm{GaN}$ представлял собой массив монокристаллических микрополос.

Согласно экспериментальным данным, применение наноструктурированной $V$-образной поверхности $\mathrm{Si}(100)$ с суб-100 $\mathrm{nm}$ периодом приводит к росту слоя полуполярного $\mathrm{GaN}$. На рис. 3 изображена предлагаемая схема формирования (1011) $\mathrm{GaN}$ на поверхности $N P-\mathrm{Si}(100)$. Видно (рис. 3,a), что асимметрия канавок $N P-\mathrm{Si}$ как следствие асимметрии WOS-наномасок присутствует. Это означает, что в массиве одни склоны V-наноканавок имеют преимущество по площади в выходе грани $\mathrm{Si}(111)$ по сравнению с противоположными

4 Письма в ЖТФ, 2018, том 44, вып. 12 
склонами. Зародышеобразование гексагонального AlN происходит преимущественно на гранях $\mathrm{Si}(111)$ [17]. Как известно, формирование гетероэпитаксиального слоя AlN на обеих сторонах наноканавки начинается с образования зародышей, которые разрастаются и образуют сплошной первичный слой (дальнейший рост слоя будет уже гомоэпитаксиальным). Скорость гомоэпитаксиального роста будет существенно выше скорости гетероэпитаксиального. Наноразмерность канавок, в которых расстояние между наклонными стенками меняется от $\sim 20$ до $\sim 80 \mathrm{~nm}$ с глубиной до $45 \mathrm{~nm}$ (т.е. среднее отношение ширина/глубина $\sim 1$ ), по нашему мнению, обеспечивает как снижение потоков атомов $\mathrm{Al}$ и $\mathrm{N}$ к поверхности, так и быстрый диффузионный обмен атомов $\mathrm{Al}$ и $\mathrm{N}$ между соседними противоположными стенками $V$-наноканавки. За счет последнего даже при небольшой разнице в площади поверхности грани $\operatorname{Si}(111)$ на одной из сторон $V$-канавок на соответствующих их сторонах в массиве быстрее сформируется гомоэпитаксиальный слой AlN (рис. 3,b). Последующий синтез GaN будет происходить уже только на сплошном слое $\mathrm{AlN}$, и образуется слой, направление роста которого перпендикулярно плоскости грани $\mathrm{Si}(111)$ и отклонено на угол $62^{\circ}$ от оси $c$ полярного направления (рис. $\left.3, c\right)$. Таким образом, наличие описанных выше подложек $N P-\operatorname{Si}(100)$ в сочетании с небольшой скоростью поставки реагентов к поверхности приводит к синтезу полуполярного слоя $\mathrm{GaN}$ на всей площади подложки (рис. $2, b$ ).

Гетероэпитаксия $\mathrm{GaN}$ на подложке $\mathrm{Si}(100)$ c $V$-образной структурированной поверхностью с суб-100 $\mathrm{nm}$ размерами элементов приводит к конкуренции при зарождении AlN на стенках канала и последующему росту слоя $\mathrm{GaN}$ в одном полуполярном направлении.

Исследование выполнено при частичной финансовой поддержке РФФИ в рамках научного проекта № 16-08-00208.

\section{Список литературы}

[1] Wang T. // Semicond. Sci. Technol. 2016. V. 31. P. 093003.

[2] Akasaka T., Kobayashi Y., Makimoto T. // Appl. Phys. Lett. 2007. V. 90. P. 121919.

[3] Liu J.-M., Zhang J., Lin W.-Y., Ye M.-X., Feng X.-X., Zhang D.-Y., Ding S., Xu C.-K., Liu B.-L. // Chin. Phys. B. 2015. V. 24. P. 057801.

[4] Dadgar A. // Phys. Status Solidi B. 2015. V. 252. P. 1063-1068.

Письма в ЖТФ, 2018, том 44, вып. 12 
[5] Ravash R., Blaesing J., Dadgar A., Krost A. // Appl. Phys. Lett. 2010. V. 97. P. 142102.

[6] Hikosaka T., Narita T., Honda Y., Yamaguchi M., Sawakia N. // Appl. Phys. Lett. 2004. V. 84. P. 4717-4719.

[7] Abe Y., Komiyama J., Isshiki T., Suzuki S., Yoshida A., Ohishi H., Nakanishi H. // Mater. Sci. Forum. 2009. V. 602-603. P. 1281-1284.

[8] Dinh D.V., Presa S., Akhter M., Maaskant P.P., Corbett B., Parbrook P.J. // Semicond. Sci. Technol. 2015. V. 30. P. 125007.

[9] Bessolov V., Kalmykov A., Konenkova E., Kukushkin S., Myasoedov A., Poletaev N., Rodin S. // J. Cryst. Growth. 2017. V. 457. P. 202-206.

[10] Honda Y., Kawaguchi Y., Ohtake Y., Tanaka S., Yamaguchi M., Sawaki N. // J. Cryst. Growth. 2001. V. 230. P. 346-350.

[11] Chen G.T., Chang S.P., Chui J.I., Chang M.N. // Appl. Phys. Lett. 2008. V. 92. P. 241904.

[12] Chen L., Payne J., Strate J., Li C., Zhang J.-M., Yu W.-J., Di Z.-F., Wang X. // Chin. Phys. B. 2015. V. 24. P. 118102.

[13] Huang C.C., Chang S.J., Kuo C.H., Wu C.H., Ko C.H., Wann C.H., Cheng Y.C., Lind W.J. // J. Electrochem. Soc. 2011. V. 158. P. H626-H629.

[14] Smirnov V.K., Kibalov D.S., Orlov O.M., Graboshnikov V.V. // Nanotechnology. 2003. V. 14. P. 709-715.

[15] Smirnov V.K., Kibalov D.S. // Proc. of the XXI Int. Conf. „Ion-surface interactions“. Yaroslavl, Russia, 2013. V. 1. P. 62-66.

[16] Рожсавская М.М., Лундин В.В., Заварин Е.Е., Трошков С.И., Брунков П.Н., Цаиульников А.Ф. // ФТП. 2013. Т. 47. В. 3. С. 414-419.

[17] Lee S.C., Sun X.Y., Hersee S.D., Brueck S.R.J. // J. Cryst. Growth. 2005. V. 279. P. 289-292.

4* Письма в ЖТФ, 2018, том 44, вып. 12 